\title{
Evaluation of Amitraz, Against Ticks and Mites Infestation in Cattle and Sheep in Comparison With Diazinon and Deltamethrin
}

\author{
M. A. F. Abdel-Fattah ${ }^{1}$, K. El-Kholany ${ }^{2}$ \\ ${ }^{1}$ Department of Pharmacology, Faculty of Veterinary Medicine, Suez Canal University, Ismailia, Egypt \\ ${ }^{2}$ Department of Parasitology, Animal Health Research Institute (Zagazig branch), Zagazig, Egypt
}

\begin{abstract}
Evaluation of amitraz against ticks and mites infestation in cattle and sheep in comparison with diazinon and deltamethrin was performed. Amitraz showed over $95 \%$ inhibition of oviposition and hatching of laid eggs at dilution of 1:500 while diazinon and deltamethrin produced around $90 \%$ inhibition of oviposition at the same dilution. Fed ticks were more susceptible for all tested acaricides than the unfed ticks, where amitraz reached its full effectiveness $(100 \%$ kill of fed and unfed) 2 weeks after application while diazinon and deltamethrin produced over $90 \%$ at the same dilution. Spraying application of amitraz $12.5 \%$ resulted in $100 \%$ tick control by day 5 and the effect was maintained for further $\mathbf{2 8}$ days whereas diazinon and deltamethrin were fully effective by days 9 and 13, respectively and their efficacy were maintained for 16 and 20 days, respectively. Spraying application of amitraz $12.5 \%$ produced $100 \%$ efficacy as no live mites were found on day 17 and maintained in full effectiveness till day 33 where respraying was needed. In conclusion, amitraz produced rapid detachment of ticks from animals; its residual effect was long and protected animals from re-infestation for 29 days and was able to eradicate psoroptes mite infestation in sheep.
\end{abstract}

Ectoparasites represent one of the major problems affecting animal health, productivity and of zoonotic importance. For example, ticks can cause harm to its host through blood sucking and transmit many pathogenic organisms, which cause animal diseases such as myiasis, spotted fever, theileriosis, babesiosis, anaplasmosis and lyme disease (Kocan and Kocan, 1991).

Mange is another ectoparasitic disease, caused by presence of microscopic acarids in the central layer or on the surface of the skin. It affects many species of domestic animals including cattle and sheep. Economically, great losses can result from external parasitic infestation as loss of wool production and body weight, decrease of milk and meat yields, reduction of leather quality and impaired reproductive performance in addition to the cost of control and treatment (Fthenakis et al., 2001). Ectoparasites on the host can be accomplished by the direct application of acaricide to the animal's hair or skin. Ideal insecticide should destroy all parasitic stages of life cycle, relatively non-toxic, of no residues in meat, milk and other animal products that used for human consumption (Murphy, 1989).

Amitraz is a formamidine derivative insecticide, which targets ticks, and mites without harming beneficial insects, currently approved for use on livestock by the U.S. Environmental Protection Agency (EPA) and classified as non-toxic. Studies proved that it is effective against pests that have developed resistance to organophosphates and carbamates insecticides. This prompted us to evaluate amitraz as an acaricide in cattle and sheep mite in comparison with deltamethrin and diazinon.

\section{Material and Methods}

Animals.

Sheep. Thirty-five Balady sheep, weighing between $35-45 \mathrm{~kg}$, naturally infested with mite in Sharkia Province were used in this study.

Cows. Twenty-nine Balady cows weighting between $200-350 \mathrm{~kg}$ and heavily infested with ticks on their coat and udder reared at one farm located in Sharkia province were used in the study.

Chemicals.

Amitraz 12.5\%. It was obtained from Egyptian Company for Chemical and Pharmaceuticals (ADWIA), El-Obour City, Egypt.

Butox (Deltamethrin 25 ppm). It was purchased from Intervet, Netherland.

Diazinon $60 \%$. It was purchased from Sedico Co. $6^{\text {th }}$ October City, Egypt.

Experiments.

In vitro evaluation of Insecticide. Ticks were collected according to the technique 
of (Roulston and Wilson, 1965) and identified according to the method of (Walker, 1994) using description and illustration keys. Insecticidal activity of each chemical was assessed according to: A) Percentage of death in the treated ticks for each insecticide dilution.

B) The number of eggs laid by the treated ticks and subsequent hatching percentage.

Briefly, for each insecticide concentration $20 \mathrm{gm}$ of ticks (correspond to 57-72 acarids) were used. The female ticks were immersed in $50 \mathrm{ml}$ of the insecticide solution for $3 \mathrm{~min}$, placed in Petri dish and placed in incubator $\left(27^{\circ} \mathrm{C}\right.$ and $90 \%$ humidity). The number of female still capable of egg laying was determined 3 weeks after treatment as well as the hatchability of eggs laid. Mites were collected by Alkali Maceration technique according to the method of (Solusby, 1982) and identified by the help of the method described by (Lonneux and Losson, 1992). Briefly, mites were collected by skin scraping from different lesions on the animal body. The peripheral parts of the lesions were moistened with glycerin to soften the keratinized layers of the skin and then the lesion was scarped with a clean sharp scalpel until blood oozing.

Field evaluation of Insecticide.

Cattle tick infestation. Amitraz, butox and diazinon were prepared for use. They were diluted to dilutions recommended by the manufacturer and applied by spraying method. Field trials with the tested insecticide were conducted on animals naturally infested with ticks according to the technique described by (Health et al., 1980). Cattle were randomly allocated into 4 groups (5 cows in group one and 8 animals/group in groups 2, 3, and 4). The animals in group one were left as non-treated control while animals in groups 2,3 , and 4 were treated with amitraz, deltamethrin and diazinon respectively. The calculated volume of insecticide was added to small amount of water, stirred vigorously to obtain homogenous emulsion and the remaining amount of water was gradually added to obtain the required dilution. Animals were sprayed with motor sprayer and spray's nozzle was hold at $20 \mathrm{~cm}$ distance from the animal body, starting on one side near the head and continued to the other side from above to downward until dipping of the emulsion occurred. Focusing was paid to the predilection sites of the parasites such as under the tail, inner aspects of thighs, abdomen, udder and perineal regions. Control animals were sprayed with water only.

Sheep mite infestation. Naturally infested sheep were randomly allocated into 4 groups (5 sheep in group one and 10 animals/group in groups 2, 3 , and 4). Animals in group one were left as nontreated control while animals in group 2, 3, and 4 were treated with amitraz, deltamethrin and diazinon respectively. Control of mange mites was carried out according to the method described by (Coles and Stafford, 1999), before treatment at $(0)$ time and after treatment at $1^{\text {st }}$ day and regularly every four days. Standard skin scarping $(6 \mathrm{~cm}$ area) were taken from mange lesions in clean Petri dishes from both treated and control animals then counting the number of living mites under the microscope before and after insecticide application.

Animal houses were sprayed using half the dilution applied on infested animals as it is considered as foci of ectoparasites re-infestation.

\section{Results}

Tick Identification.

Collected ticks were identified as Genus Boophilus annulatus as they have no pigmented pattern on the integument, mouthparts are very short and the pulps have an appearance of two sections formed as protruding rings. The second segment does not extend beyond the margin of the basis capituli. The eyes are present. The anal groove that is present posterior to the anus and the coxa is without long spurs (Fig. 1). According to (Mc-Daniel, 1979), Males have no caudal appendage and female's coax are with shallow, rounded emargination separating internal and external spur (Fig. 1).

Effects of different insecticides on Boophilus annulatus tick infesting cattle.

Application of amitraz in heavily infested cattle (Fig. 2) produced over $95 \%$ inhibition of oviposition and hatching of laid eggs at dilution of 1:500 and the efficacy decreased but still over $90 \%$ at dilution of 1:700 (Table 1). Diazinon application inhibited tick oviposition and hatching of laid eggs and its effectiveness was above $90 \%$ at dilutions of 1:500 and 1:700 whereas deltamethrin had the same efficacy at dilution of 1:500 only (Table 1). Fed ticks were more susceptible for all insecticide tested than the unfed ticks. Amitraz was the most effective one (i.e. $100 \%$ killing) after 2 weeks of its 
Table (I): Laboratory trials of the effect of different dilutions of Amitraz, Deltamethrin (Butox) and Diazinon on oviposition and egg hatch ability of $B$. annulatus ticks infesting cattle.

\begin{tabular}{ccccccccccccc}
\hline Parameter & \multicolumn{3}{c}{ Ticks laid eggs \% } & \multicolumn{4}{c}{$\begin{array}{c}\text { Average no. of eggs } \\
\text { laid/tick }\end{array}$} & \multicolumn{3}{c}{$\begin{array}{c}\text { Average No of eggs } \\
\text { hatched }\end{array}$} & \multicolumn{3}{c}{ Hatching eggs \% } \\
\hline Dilutions & Amz & Butox & Diaz & Amz & Butox & Diaz & Amz & Butox & Diaz & Amz & Butox & Diaz \\
$\mathbf{1 : 5 0 0}$ & 3.3 & 7.8 & 6.1 & 44.6 & 81.7 & 69.3 & 1.0 & 4.2 & 2.5 & 2.24 & 5.14 & 3.61 \\
$\mathbf{1 : 7 0 0}$ & 7.2 & 19.1 & 9.1 & 55.3 & 146.3 & 94.7 & 2.7 & 10.1 & 6.8 & 4.88 & 6.96 & 7.18 \\
$\mathbf{1 : 1 5 0 0}$ & 14.8 & 23.7 & 17.4 & 117.1 & 251.1 & 189.1 & 11.6 & 33.6 & 25.7 & 9.91 & 13.38 & 13.59 \\
$\mathbf{1 : 3 0 0 0}$ & 31.3 & 67.1 & 44.7 & 183.5 & 277.1 & 233.5 & 18.4 & 53.7 & 38.8 & 10.03 & 19.38 & 16.6 \\
Control & 98.3 & 97.8 & 94.7 & 1123.3 & 912.7 & 992.8 & 996.8 & 901.3 & 886.3 & 88.7 & 98.7 & 89.27 \\
\hline
\end{tabular}

$\mathrm{Amz}=$ Amitraz. Diaz $=$ Diazino

application at dilutions of 1:500 and 1:700 whereas deltamethrin and diazinon killed 97.9 and $98.6 \%$ at dilution of $1: 500$ by the end of 2 weeks (Table 2).

Spraying application of amitraz $12.5 \%$ resulted in $100 \%$ tick control on day 5 and the effect was maintained for a further 28 days where re- spraying was needed. There was a significant difference between the mean number of ticks between animals treated with amitraz and those treated with deltamethrin and diazinon. The complete effectiveness of deltamethrin was obtained by day 13 and persisted for further 16 days whereas diazinon produced its $100 \%$ control of tick by day 9 and re-spraying was needed by day 29 (Table 3 ).

Microscopical examination of skin scrapping revealed presence of Sarcoptiform pretarsi with a long segmented caruncle (Fig. 3). Sheep infested with mite appeared emaciated, wool becomes loose and fall out by the animal's biting or scratching (Fig. 4a, b) and blood oozes from infected area in severe cases (Fig. 5).

Spraying application of amitraz at concentration of $125 \mathrm{~g} / 1$ produced significant efficacy that reached above $90 \%$ by day 13,17 and 19 and was fully effective $(100 \%)$ by day $21,25,29$ and 33 and re-growth of the wool in the lesion area was detected (Fig. 6). diazinon and Deltamethrin produced their full efficacy by days 25 and 29, respectively and re-spraying were needed by day 37 for both agents (Table 4).

\section{Discussion}

The obtained in vitro results indicated that amitraz inhibited tick oviposition and hatching of laid eggs. These results are in agreement with the data reported by (Natala et al., 2005) who found that amitraz have a quick knock-down effect on larvae and nymphs and showed a 100 $\%$ inhibition of oviposition and hatching of laid eggs at concentration of $0.04 \%$. In addition, they reported that susceptibility of unfed and fed stages of larvae, nymph and adult females of Amblyomma variegatum ticks was $100 \%$ to amitraz at the same concentration. The present study also showed that fed and unfed adult ticks differed significantly in their susceptibility to insecticides used where they are more susceptible for amitraz followed by diazinon then Deltamethrin, based on the number of dead tick after one day, one and two weeks after application. Such results may be explained by the experiment conducted by (Mekonnen et al., 2002) on one, two, and three-host ticks using Shaw larval Immersion Test method and demonstrated a higher level of resistance to cypermethrin and chlorfenvinphos but not against amitraz. Additionally, (Foil et al., 2004) demonstrated the mechanism of resistance for pyrethroids which targeted the mutation of the $\mathrm{Na}^{+}$channel and in case of organophosphates, acetylcholinestrase and P450 monooxygenase activity were involved in the development of resistance. These mechanisms for development of resistance are not included in the mode of action of amitraz.

The present results in vivo revealed that 92 $\%$ of ticks were rapidly detached within the first $24 \mathrm{~h}$ with longer protection duration (28 days), which are significantly different from that of animals sprayed with deltamethrin and diazinon infested with ticks. Such results are consistent with that is reported by (Estrada-Pena and Reme, 2005; Estrada-Pena and Ascher, 1999 and Kagaruki, 1996) who demonstrated the rapid effectivness of amitraz against cattle and dog ticks. The quick knockdown effect of amitraz and rapid detachment of ticks from treated animals were due to the mode of action of this acaricide. Amitraz acts by a unique mechanisms as agonist on alpha2-adrenoceptors (Costa et al., 1988) and octopamine receptor (Roeder et al., 
Table (2): Fatality \% of Boophiluse annalatus ticks treated with Amitraz, deltamethrin and diazinon in the laboratory.

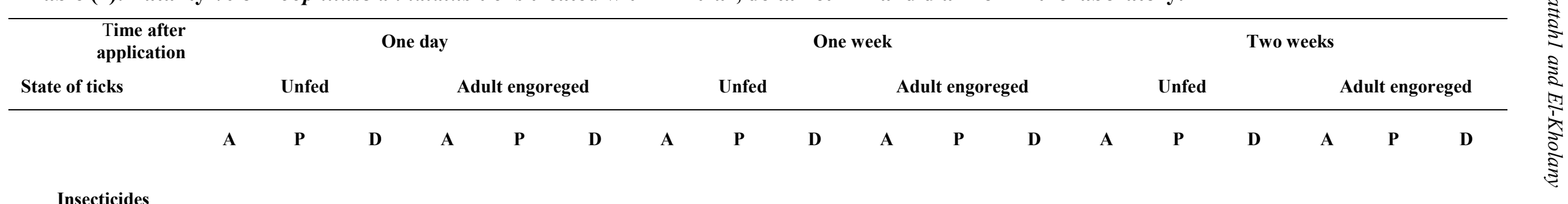

Amitraz

\begin{tabular}{|c|c|c|c|c|c|c|c|c|c|c|c|c|c|c|c|c|c|c|}
\hline 1:500 & - & 81.7 & 18.3 & - & 77.9 & 22.1 & - & 38.7 & 61.3 & - & 17.8 & 82.2 & - & - & 100 & - & - & 100 \\
\hline $1: 700$ & - & 86.4 & 13.6 & - & 80.7 & 19.3 & - & 43.3 & 56.7 & - & 26.5 & 73.5 & - & - & 100 & - & - & 100 \\
\hline 1500 & 2.3 & 93.3 & 6.7 & 0.7 & 85.9 & 8.4 & 0.7 & 52.4 & 46.9 & - & 33.9 & 66.1 & 0.6 & 5.7 & 93.7 & 0.3 & 2.5 & 97.2 \\
\hline
\end{tabular}

Deltamethrin

\begin{tabular}{|c|c|c|c|c|c|c|c|c|c|c|c|c|c|c|c|c|c|c|}
\hline 1:500 & - & 91.4 & 8.6 & - & 88.3 & 11.7 & - & 58.2 & 41.8 & - & 34.3 & 65.7 & - & 5.8 & 94.2 & - & 2.1 & 97.9 \\
\hline 1:700 & - & 96.1 & 3.9 & - & 90.4 & 9.6 & - & 62.9 & 37.1 & - & 39.7 & 60.3 & 1.1 & 9.7 & 89.2 & 0.6 & 3.3 & 94.1 \\
\hline $1: 1500$ & 9.1 & 89.8 & 1.1 & 3.4 & 91.2 & 5.4 & 6.5 & 66.6 & 26.9 & 2.8 & 46.1 & 51.1 & 5.9 & 13.4 & 80.7 & 2.7 & 9.1 & 88.2 \\
\hline
\end{tabular}

Diazinon

\begin{tabular}{|c|c|c|c|c|c|c|c|c|c|c|c|c|c|c|c|c|c|c|}
\hline $1: 500$ & - & 88.3 & 11.7 & - & 81.3 & 18.7 & - & 46.7 & 53.3 & - & 22.4 & 77.6 & - & 1.8 & 98.2 & - & 1.4 & 98.6 \\
\hline $1: 700$ & - & 91.7 & 8.3 & - & 84.9 & 15.1 & - & 51.2 & 48.8 & - & 32.1 & 67.9 & - & 6.7 & 93.3 & - & 3.7 & 96.3 \\
\hline $1: 1500$ & 1.7 & 95.1 & 3.2 & - & 89.7 & 10.3 & 0.8 & 59.1 & 40.1 & 2.2 & 42.8 & 55.2 & 1.9 & 9.7 & 88.4 & 1.6 & 6.7 & 91.7 \\
\hline Control & 100 & - & - & 100 & - & - & 100 & - & - & 100 & - & - & 100 & - & - & 100 & - & - \\
\hline
\end{tabular}

$\mathrm{A}=$ Alive $\quad \mathrm{P}=$ Paralysed $\quad \mathrm{D}=$ Dead


Table (3): Treatment of Boophilus annulatus infesting cattle using Amitraz, Deltamethrin and Diazinon.

\begin{tabular}{|c|c|c|c|c|c|c|c|c|c|c|c|c|c|c|}
\hline \multirow{2}{*}{ Insecticides } & \multirow{2}{*}{ Parameters } & \multicolumn{13}{|c|}{ Time after treatment (days) } \\
\hline & & $\mathbf{0}$ & 1 & 5 & 9 & 13 & 17 & 21 & 25 & 29 & 33 & 37 & 41 & 45 \\
\hline \multirow{2}{*}{ Amitraz } & - Average no. of ticks & 160.3 & 12.8 & - & - & - & - & - & - & - & 8.2 & - & - & - \\
\hline & - Efficacy \% & -9 & 92.1 & 100 & 100 & 100 & 100 & 1001 & 100 & 100 & 94.8 & 100 & 100 & 100 \\
\hline \multirow{2}{*}{ Deltamethrin } & - Average no. of ticks & 152.7 & 86.1 & 49.4 & 17.9 & - & - & - & - & 9.1 & & - & - & 4.5 \\
\hline & - Efficacy \% & - & 43.6 & 67.6 & 88.2 & 100 & 100 & 100 & 100 & 94 & 100 & 100 & 100 & 97 \\
\hline \multirow{2}{*}{ Diazinon } & - Average no. of ticks & 180.4 & 75.7 & 13.7 & - & - & - & - & - & 1.7 & & - & - & 3.7 \\
\hline & - Efficacy \% & - & 58 & 92.4 & 100 & 100 & 100 & 100 & 100 & 98.5 & 100 & 100 & 100 & 97.6 \\
\hline Control & - Average no. of ticks & 167.5 & 180 & 194 & 220 & 246 & 274.3 & 303.7 & 7327 & 341 & 366.7 & 391.6 & 421 & 446 \\
\hline
\end{tabular}

$\downarrow=$ Re-spraying

Table (4): Treatment of psosoptes mite infesting sheep using Amitraz, Deltamethrin and Diazinon

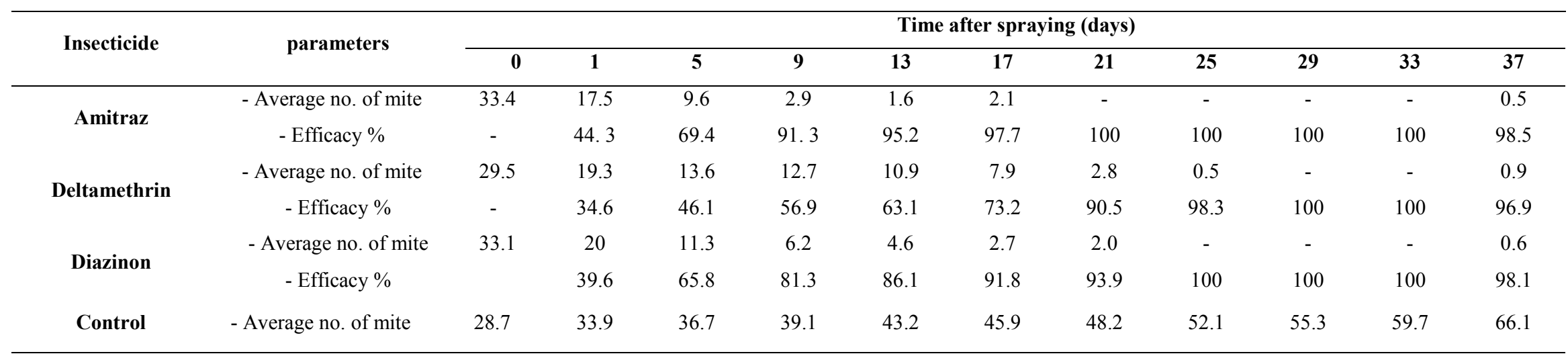

Average number of living mite in $6 \mathrm{~cm}$ area of mange lesions in infested animals were counted 

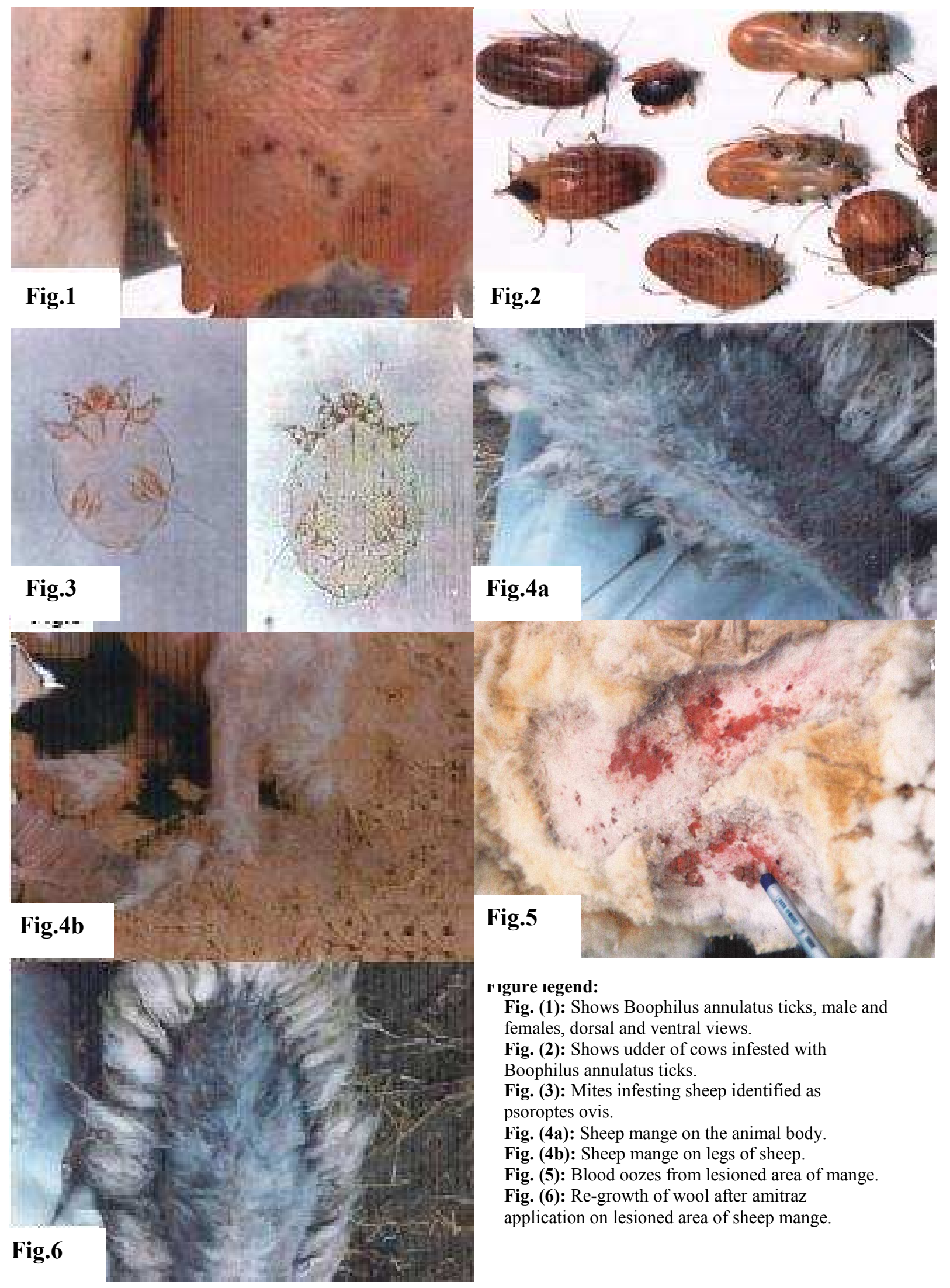

rigure regend:

Fig. (1): Shows Boophilus annulatus ticks, male and females, dorsal and ventral views.

Fig. (2): Shows udder of cows infested with Boophilus annulatus ticks.

Fig. (3): Mites infesting sheep identified as psoroptes ovis.

Fig. (4a): Sheep mange on the animal body.

Fig. (4b): Sheep mange on legs of sheep.

Fig. (5): Blood oozes from lesioned area of mange.

Fig. (6): Re-growth of wool after amitraz application on lesioned area of sheep mange. 
1995) of the insect which is thought to modify the tonic contractions in parasite muscles and since (Baxter and Barker, 1999) isolated cDNA for the octopamine receptor from cattle ticks, it seems that amitraz produces its acaricide effect through this way. In addition, (Booth, 1989) demonstrated that oviposition in cattle tick was arrested by octopamine and alpha-adrenergic agonist and both are involved in the mechanism of action of amitraz. Moreover, It also inhibits monoamine oxidase enzyme activity, which metabolizes amines in ticks and mites (Fowle and Ross, 1984).

The high activity of amitraz against mite infestation which was recorded in this study was consistent with that is reported by (Curtis, 2004 and Johnson and Boray, 1989) who evaluated amitraz and proved its efficacy against mite infestation in dogs and large animals. The less effectiveness of deltamethrin reported in our study is consistent with (James et al., 1993) who demonstrated resistance to synthetic pyrethroids in South Australia. Moreover, (Coles and Stafford, 1999) demonstrated that mites failed to die 24 hours after one-minute dip in working concentration of flumethrin sheep dip.

In conclusion, amitraz produced rapid detachment of ticks from animals; its residual effect was long and protected animals from reinfestation for 29 days and was able to eradicate psoroptes infestation of sheep.

\section{References}

American Veterinary Medical Association (1990): Zoonosis Updates pp.139.

Baxter, G. D. and Barker, S. C. (1999): Isolation of cDNA for an octopamine-like, G-protein coupledreceptor from the cattle tick, Boophilus microplus. Insect Biochem. Mol. Biol., 29: 461-467.

Booth, T. F. (1989): Effects of biogenic amines and adrenergic drugs on oviposition in the cattle tick Boophilus: evidence for octopaminergic innervation of the oviduct. Exp. Appl. Acarol., 7: 259-266.

Coles, G. C. and Stafford, K. A. (1999): The in vitro response of sheep scab mite to pyrethroid insecticides. Vet. Parasitol., 83: 327-330.

Costa, L. G.; Olibet, R. J. and Murphy, S. D. (1988): Alpha2-adrenoceptors as a target for formamidine pesticides: in vitro and in vivo studies in mice. Toxicol. Appl. Pharmacol., 93: 319-328.

Curtis, C. F. (2004): Current trends in the treatment of Sarcoptes, Cheyletiella and Otodectes mite infestation in dogs and cats. Vet. Dermatol., 15: 108-114.

Estrada-Pena, A. and Reme, C. (2005): Efficacy of a collar impregnated with amitraz and pyriproxyfen for prevention of experimental tick infestations by Rhipicephalus sanguineus, Ixodes ricinus and Ixodes scapularis in dogs. J. Am. Vet. Med. Assoc., 226: 221-224.

Estrada-Pena, A. and Ascher, F. (1999): Comparison of an amitraz-impregnated collar with topical administration of fibronil for prevention of experimental and natural infestations by the brown dog tick (Rhipicephalus sanguineus). J. Am. Vet. Med. Assoc., 214: 1799-1803.

Foil, L. D.; Coleman, P.; Eisler, M.; Fragoso-Sanchez, H.; Garcia-Vazquez, Z.; Guerrero, F. D.; Jonsson, N. N.; Langstaff, I. G.; Li, A. Y.; Machila, N.; Miller, R. J.; Morton, J.; Pruett, J. H. and Torr, S. (2004): Factors that influence the prevalence of acaricide resistance and tickborn diseases. Vet. Parasitol., 125: 163-181.

Fowle, C. J. and Ross, S. B. (1984): Selective inhibitors of monoamine oxidase $\mathrm{A}$ and $\mathrm{B}$, biochemical, pharmacological and clinical properties. Med. Res. Rev., 4:335358.

Fthenakis, G. C.; Karagiannides, A.; Alexopoulos, C.; Brozos, C. and Papadopoulos, E. (2001): Effect of sarcoptic mange on the reproductive performance of ewes and transmission of Sarcoptes scabiei to newborn lams. Vet. Parasitol., 95: 63-71.

Health, A. C. G.; Tenquist, J. D. and Bishop, D. M. (1980): Effect of pour-on organophosphate insecticides and a diamidicide acaricide on cattle ticks jaemaphysalis longicornis. New Zealand J. Exp. Agric., 8: 79-87.

James, P. J.; Saunders, P. E.; Cockrum, K. S. and Munro, K. J. (1993): Resistance to synthetic pyrethroide in South Australian population of sheep lice (Bovicola ovis) Aust. Vet. J., 70: 105-109.

Johnson, P. W. and Boray, J. C. (1989): Efficacy of potential acaricide against the sheep itch mite (Psorergates ovis) with different application techniques In Veterinary Therapeutics, Proc. Sci. Meeting, Chapter of Vet. Pharmacol., Aust. College Vet. Scientists, pp. 129.

Kagaruki, L. K. (1996): The efficacy of amitraz against cattle ticks in Tanzania. Onderstepoort J. Vet. Res., 63: 9196.

Kocan, A. and Kocan, K. M. (1991): Tick-transmitted protozoan diseases of wildlife in North Amrica. Bull. Soc. Vector Ecol., 16: 94-108.

Lonneux, J. F. and Losson, B. (1992): Field efficacy of injectable and pour-on moxidectin in cattle naturally infested with Psoroptes ovis (Acarina: Psoroptidae). Vet. Parasitol., 45: 147-152.

Mc-Daniel, B. (1979): How to know mites and ticks? South Dakota State Univ., the Picture Key Nature Series, Wm. C. Brown Comp. Publisher. Dubuque, Iowa.

Mekonnen, S.; Bryson, N. R.; Fourie, L. J.; Peter, R. J.; Spickett, A. M.; Taylor, R. J.; Strydom, T. and Horak, I. G. (2002): Acaricide resistance profiles of single- and multi-host ticks from communal and commercial farming areas in the easter Cape and North-West Provinces of South Africa. Onderstepoort J. Vet. Res., 69: 99-105.

Murphy, S. D. (1989): Pesticides, Ch. 17 in Toxicol., the basic science of poisons, eds. Casarett, L. J. And Doull, J. Macmillan publishing Co. Inc., Ny 1075.

Natala, A. J.; Agyei, A. D. and Awumbila, B. (2005): Susceptibility of Amblyomma variegatum ticks to acaricides in Ghana. Exp. Appl. Acarol., 35:259-268.

Roeder, T. (1995): Pharmacology of the octopamine receptor from locust central nervous tissue (OAR3). Br. J. Pharmacol., 114: 210-216.

Roulston, W. J. and Wilson, J. T. (1965): Chemical control of cattle tick Boophilus microplus. J. Bull. Entom. Res., 55: 617-635.

Solusby, F. J. (1982): Helminth, Arthropods and Protozoa of domesticated animals. $7^{\text {th }}$ ed. The English Language book Soc. and Baillers. Timdall London.

Walker, A. (1994): The Arthropods of humans and domestic animals: A guide to preliminary identification. Edmundsbury Press., Great Britain. 
